\title{
Differential gene methylation patterns in cancerous and non-cancerous cells
}

\author{
KATARZYNA KAMIŃSKA $^{1,2}$, ANETA BIAŁKOWSKA ${ }^{1}$, JANUSZ KOWALEWSKI ${ }^{2}$, \\ SUI HUANG ${ }^{3}$ and MARZENA A. LEWANDOWSKA ${ }^{1,2}$
}

\author{
${ }^{1}$ Department of Molecular Oncology and Genetics, Innovative Medical Forum, \\ The F. Lukaszczyk Oncology Center; ${ }^{2}$ Department of Thoracic Surgery and Tumors, \\ The Ludwik Rydygier Collegium Medicum, Nicolaus Copernicus University, 85-796 Bydgoszcz, Poland; \\ ${ }^{3}$ Department of Cell and Molecular Biology, Northwestern University Feinberg School of Medicine, \\ Chicago, IL 60611, USA
}

Received January 11, 2019; Accepted April 8, 2019

DOI: $10.3892 /$ or.2019.7159

\begin{abstract}
Large-scale projects, such as The Cancer Genome Atlas (TCGA), Human Epigenome Project (HEP) and Human Epigenome Atlas (HEA), provide an insight into DNA methylation and histone modification markers. Changes in the epigenome significantly contribute to the initiation and progression of cancer. The goal of the present study was to characterize the prostate cancer malignant transformation model using the $\mathrm{CpG}$ island methylation pattern. The Human Prostate Cancer EpiTect Methyl II Signature PCR Array was used to evaluate the methylation status of 22 genes in prostate cancer cell lines: PC3, PC3M, PC3MPro4 and PC3MLN4, each representing different metastatic potential in vivo. Subsequently, it was ascertained whether DNA methylation plays a role in the expression of these genes in prostate cancer cells. Hypermethylation of $A P C, D K K 3, G P X 3, G S T P 1$, MGMT, PTGS2, RASSF1, TIMP2 and TNFRSF10D resulted in downregulation of their expression in prostate cancer cell lines as compared to WT fibroblasts. Mining of the TCGA data deposited in the MetHC database found increases in the methylation status of these 9 genes in prostate cancer patients, further supporting the role of methylation in altering the expression of these genes in prostate cancer. Future studies are warranted to investigate the role of these proteins in prostate cancer development.
\end{abstract}

Correspondence to: Professor Marzena A. Lewandowska, Department of Molecular Oncology and Genetics, Innovative Medical Forum, The F. Lukaszczyk Oncology Center, Romanowskiej 2, 85-796 Bydgoszcz, Poland

E-mail: lewandowskam@co.bydgoszcz.pl

Key words: epigenetics, DNA methylation, gene expression, prostate cancer, epigenetic regulation of transcription

\section{Introduction}

Prostate cancer $(\mathrm{PCa})$ is a heterogeneous, multifaceted and biologically complex disease. Changes in the cancer genome and epigenome have been extensively studied in recent years using innovative high throughput methods. Projects aimed at accelerating the expansion of knowledge concerning the genetic landscape of cancer, including PCa, were launched with various platforms based on next-generation sequencing (NGS) and microarrays to discover molecular aberrations at the DNA, RNA, protein and epigenetic levels. The main and first large-scale cancer genomic project was The Cancer Genome Atlas (TCGA) (https://cancergenome.nih.gov/). A pilot study of TCGA started approximately 10 years ago to discover major genetic alterations in large cohorts of selected tumors, i.e. brain, lung, ovarian cancer. Phase II of the project was expanded to over 30 human tumors including prostate adenocarcinoma (1). The comprehensive characterization of 333 primary prostate cancers in the TCGA Network revealed novel molecular features (1). Methylation of $\mathrm{CpG}$ islands in gene promoters is the main epigenetic mechanism for gene expression silencing. Aberrant methylation pattern, e.g., increased methylation frequency of tumor-suppressor genes, is a common molecular feature of the majority of human cancers including prostate cancer (2). Genes that protect cells from neoplastic transformation are not only known as tumor suppressors, but often their products function as tumor cell invasion factors and are involved in cell metabolism and DNA repair. Failure of these functions leads to carcinogenesis (3).

The necessity for precise prostate cancer diagnostics and disease prognosis encourages the search for novel biomarkers and basic scientific research. Microarray-based gene signatures are used for cancer diagnostics, tumor classification and prognosis, and prediction of response to therapies $(4,5)$. There are several types of signatures that have been evaluated for cancer diagnostics: Based on gene expression-in the breast (5), colon (6) and lung cancers (7); based on methylation analysis-in colon cancer (8); and based on miRNA expression data (9). Profiling in prostate cancer is still at the exploration stage. 
The aim of the present study was to evaluate the gene methylation profile using a prostate cancer cell line model and The Human Prostate Cancer EpiTect Methyl II Signature PCR Array designed to evaluate the following genes: $A P C, C A V 1$, CDH1, CDKN2A, DKK3, DLC1, EDNRB, GPX3, GSTP1, MGMT, MSX1, PDLIM4, PTGS2, RARB, RASSF1, SFRP1, SLC5A8, TIMP2, TNFRSF10D, ZNF185. For our study, we chose prostate cancer cell lines PC3, PC3M, PC3MLN4 and PC3MPro4 which shared the same origin but each of them demonstrated different levels of metastatic capabilities in a mouse model of human prostate cancer. They provided a system to associate the level of expression with malignancy.

Oncogenesis is associated with abnormal regulation of those genes, which are responsible for various functions in cells, such as cell signaling, cytoskeletal architecture, cell-cell contacts, cell motility, reorganization of the extracellular matrix (ECM) and many other mechanisms. Changes in these processes are important determinants of tumor invasion and metastasis. Molecular mechanisms underlying these processes have been under evaluation in the last few years: $A P C$ (10), CAVI (11), CDKN2A (12), CDH1 (13), DLC1 (14), DKK3 (15), EDNRB (16), GPX3 (17), GSTPI (18), MGMT (19), MSX1 (20) PDLIM4 (21), PTGS2 (22), RARB (23), RASSF1 (24), SFRPl (25), SLC5A8(26), TIMP2 (27), TNFRSF10D (28), ZNF185 (29).

For our study, we chose a prostate cancer metastasis model $(30,31)$ and wild-type normal skin fibroblasts $(32,33)$. After evaluation of methylation using The Human Prostate Cancer EpiTect Methyl II Signature PCR Array, we examined the expression status of the genes to confirm whether methylation regulated them. Although several genes [for example APC (34), GPX3 (35) PDLIM4 (21)] have been analyzed in the PC3 cell line, this was the first study to use this qPCR method to describe gene expression and methylation in PC3-derived cell lines (PC3M, PC3MLN4 and PC3MPro4). Finally, gene methylation data in prostate cancer patients derived from the TCGA project were evaluated.

\section{Materials and methods}

Cell line cultures. Prostate cancer cell lines, PC3, PC3M, PC3MLN4 and PC3MPro4 (36), and reference human WT fibroblast cell lines, VH10 and VH25 $(32,33)$, were kindly provided by Professor S. Huang and Dr A. Bialkowska, respectively.Prostate cancer cell lines were cultured in cultured dishes with a growth area of $100 \mathrm{~mm}^{2}$ in L-glutamine RPMI-1640 medium (GE Healthcare Life Sciences, Marlborough, MA USA). The fibroblast cell lines (VH10 and VH25) were cultured in High Glucose DMEM medium (GE Healthcare Life Sciences). RPMI and DMEM were supplemented with $10 \%$ fetal bovine serum (GE Healthcare Life Sciences) and 1\% antibiotic/antimycotic solution (GE Healthcare Life Sciences): $100 \mathrm{U} / \mathrm{ml}$ of penicillin, $100 \mu \mathrm{g} / \mathrm{ml}$ of streptomycin and $0.25 \mu \mathrm{g} / \mathrm{ml}$ of amphotericin B. The cells were maintained at $37^{\circ} \mathrm{C}$ in a $5 \% \mathrm{CO}_{2}$ atmosphere and a relative humidity of $95 \%$.

Methylation analysis of the cell lines. Methylation analysis was performed using EpiTect Methyl II PCR Array, Signature Panel (cat. no. EAHS-051Z; Qiagen, Inc., Valencia, CA, USA) according to the manufacturer's protocol, as follows. DNA from the PC3, PC3M, PC3MLN4 and VH10 cells was isolated using QIAamp DNA FFPE Tissue Kit (Qiagen, Inc.) according to the protocol, with additional incubation with RNase A. The absence of RNA contamination was tested using agarose gel electrophoresis. Subsequently, incubation with methylation-sensitive (Ms), methylation-dependent (Md), and double (Msd) restriction endonuclease was performed. After digestion, quantitative PCR (qPCR) was performed using primer mixes pre-dispensed into 96 -wells to evaluate the methylation status of the 20 (from 22) following genes: $A P C, C A V 1, C D H 1, C D K N 2 A, D K K 3, D L C 1, E D N R B, G P X 3$, GSTP1, MGMT, MSX1, PDLIM4, PTGS2, RARB, RASSF1, SFRP1, SLC5A8, TIMP2, TNFRSF10D and ZNF185. The methylation status of selected gene promoters was analyzed using an integrated Excel-based template (SA Bioscience, Qiagen). Raw threshold cycle values of both digests along with mock digestion values were normalized, and the percentage of un/methylated DNA was automatically calculated using the MethylScreen ${ }^{\mathrm{TM}}$ technology provided under license from Orion Genomics, LLC, St. Louis, MO, USA). A heatmap was created using free on-line software-Morpheus from Broad Institute (https://software.broadinstitute.org/morpheus/).

RNA isolation and cDNA synthesis. RNA isolation was performed in the cell cultures reaching $~ 80 \%$ confluency in cultured dishes with a growth area of $100 \mathrm{~mm}^{2}$. Cells were trypsinized and centrifuged ( $300 \mathrm{x} \mathrm{g,} 5 \mathrm{~min})$, and the cell pellet was suspended in $600 \mathrm{ml}$ PBS 1X (Sigma-Aldrich; Merck KGaA, Darmstadt, Germany) and transferred into 3 tubes in equal volumes $(200 \mu \mathrm{l})$. Total RNA was isolated from each cell line in triplicates with the High Pure RNA Isolation Kit (Roche Diagnostics GmbH, Mannheim, Germany) according to the manufacturer's protocol. RNA concentration was evaluated using NanoDrop 1000 (Thermo Fisher Scientific, Inc., Waltham, MA, USA). Approximately $1 \mu \mathrm{g}$ of each RNA sample was used to synthesize complementary DNA (cDNA) with the Transcriptor High Fidelity cDNA Synthesis Kit (Roche Diagnostics $\mathrm{GmbH}$ ) according to the manufacturer's protocol with small modifications. All cDNAs were synthesized using half of the recommended volume of the anchored-oligo(dT) $)_{18}$ primer and the random hexamer primer. Denaturation the template-primer mixture was carried out by incubating the tube for $10 \mathrm{~min}$ at $65^{\circ} \mathrm{C}$ on a thermal cycler block, followed by the addition of the remaining components of the reverse transcriptase mix (RT-mix). The reverse transcription reaction was carried out at $50^{\circ} \mathrm{C}$ for $30 \mathrm{~min}$ and $85^{\circ} \mathrm{C}$ for $5 \mathrm{~min}$. The synthesized cDNA was stored at $-20^{\circ} \mathrm{C}$ until subsequent use.

cDNA purity control. The absence of genomic DNA in the cDNA samples was tested by cDNA amplification with a set of primers localized in an intron sequence ofDNA: Forward primer (Int2F, 5'-ACATGTAATTATCATGTGAATTTATTACGA-3') and reverse primer (Int2R, 5'-CTCAGAGCTTCAGTTATG GAGA-3'). The positive control was genomic DNA routinely used in the laboratory in cDNA purity testing. Agarose gel electrophoresis was performed. Lack of contamination with genomic DNA was reflected by the lack of intron amplification products for the cDNA samples.

Gene expression analysis. Quantitative reverse transcriptase real-time PCR (RT-qPCR) was performed using two 
technologies: i) TaqMan Probes-hydrolysis probes dual-labeled with a reporter fluorophore and a dark quencher dye (LightCycler ${ }^{\circledR} 480$ Probes Master, The Universal ProbeLibrary Set, Human; both by Roche Diagnostics GmbH) specific to target gene, and ii) a double-stranded DNA binding dye (LightCycler 480 SYBR-Green; Roche Diagnostics $\mathrm{GmbH})$. Analyses were performed on LightCycler 2.0 and LightCycler 480 instruments (Roche Diagnostics $\mathrm{GmbH}$ ). The PBGD (for the probe-based assay) and hMRPL19 (for the SYBR-Green assay) genes were used as a reference. Primers specific for the mRNA sequences of the analyzed genes were designed using the Universal ProbeLibrary Assay Design Center software accessible at www universalprobelibrary.com. The primers were designed to have intron-spanning sequences to avoid false-positive signals from the possible residual genomic DNA. Samples without reverse transcriptase for each cell line and samples without RNA were used as negative controls. An amount of $2 \mu \mathrm{l}$ of sample cDNA was added to each reaction with the $P B G D$ reference gene (Universal ProbeLibrary Human PBGD Gene Assay; Roche Diagnostics $\mathrm{GmbH}$ ). The Universal ProbeLibrary probe was 5'end-labeled with fluorescein (FAM) and 3'end-labeled with a dark quencher dye. The UPL Reference Gene probe was labeled with LightCycler ${ }^{\circledR}$ Yellow 555 at the 5'end and with a quencher dye near the 3'end. Real-time PCR was performed in dual color. The fluorescence signal was acquired in two detection channels: FAM $(530 \mathrm{~nm})$ and LightCycler ${ }^{\circledR}$ Yellow $555(610 \mathrm{~nm})$. Real-time PCR was conducted under the following conditions: one cycle at $95^{\circ} \mathrm{C} / 10 \mathrm{~min}$; 45 cycles of denaturation $\left(95^{\circ} \mathrm{C} / 10 \mathrm{sec}\right)$, annealing $\left(60^{\circ} \mathrm{C} / 30 \mathrm{sec}\right)$ and extension $\left(72^{\circ} \mathrm{C} / 1 \mathrm{sec}\right)$. The expression of the second reference gene $h M R P L 19$ was evaluated using SYBR-Green and $1 \mu \mathrm{l}$ of sample cDNA. PCR conditions consisted of: One cycle at $95^{\circ} \mathrm{C} / 10 \mathrm{~min} ; 45$ cycles of denaturation $\left(95^{\circ} \mathrm{C} / 10 \mathrm{sec}\right)$, annealing $\left(60^{\circ} \mathrm{C} / 20 \mathrm{sec}\right)$ and extension $\left(72^{\circ} \mathrm{C} / 5 \mathrm{sec}\right)$; one cycle of melting curve: $95^{\circ} \mathrm{C} / 5 \mathrm{sec}, 40^{\circ} \mathrm{C} / 1 \mathrm{~min}, 97^{\circ} \mathrm{C}$, according to a previous publication (37). Relative gene expression was calculated using the $\Delta \Delta \mathrm{Cq}$ method (38). Gene expression was randomly tested in triplicates using the Universal ProbeLibrary Human GAPD Gene Assay (Roche Diagnostics $\mathrm{GmbH}$ ) which accounted for the third control analysis. Any significant difference in the trends of high or low expression of the targeted gene between PBGD and $h M R P L 19$ was observed.

MethHC database. The datasets for the analysis and visualization of the methylation level of $A P C, D K K 3, G P X 3, G S T P 1$, MGMT, PTGS2, RASSF1, TIMP2, TNFRSF10D and PDLIM4 in prostate adenocarcinoma TCGA were obtained from the MethHC web base (http://methhc.mbc.nctu.edu.tw/php/index. php) and analyzed using tools available under the MethHC open access terms (39).

Statistical analysis. RNA extraction and cDNA synthesis were performed in three biological replicates for each cell line. Gene expression was analyzed at least three times for each biological replicate, and means were calculated from nine values. Promoter methylation status was analyzed in three biological replicates for each cell line. Differences in gene expression and methylation between analyzed cell lines were determined using one-way analysis of variance (ANOVA), followed by Tukey's HSD (honestly significant difference) post hoc tests in the STATISTICA Software (StatSoft, Inc. Tulsa, OK, USA). $\mathrm{P} \leq 0.05$ and $\mathrm{P} \leq 0.01$ were considered as statistically significant. Statistically significant differences between the VH10 cell line and prostate cancer cell lines were marked on the figures with asterisks. Data are presented as means with standard deviation (SD).

\section{Results}

Methylation profile. The initial data to be established were the methylation levels of genes important in the carcinogenesis process in four cell lines, non-cancerous VH10 and three prostate cancer cell lines, PC3, PC3M and PC3MLN4. The Human Prostate Cancer EpiTect Methyl II Signature PCR Array was used to analyze the methylation status of 20 out of 22 gene promoters. The kit is based on DNA treatment with a methylation-sensitive and methylation-dependent restriction enzyme followed by qPCR. It was found that hypermethylation was the major mechanism of regulation of expression of the analyzed genes (Fig. 1).

An increase in the methylation status in the promoter regions of 9 genes in the prostate cancer cell lines compared to that in the VH10 cells was observed: $A P C, C D K N 2 A, E D N R B$, RASSF1, SFRP1, SLC5A8, GPX3, PTGS2 and TIMP2 (Fig. 1). The methylation status for the first 5 genes was higher and achieved statistical significance $(\mathrm{P}<0.01)$ in all analyzed prostate cancer cell lines (PC3, PC3M and PC3MLN4) compared to the VH10 cell line and was close to $100 \%$. GPX3 showed an increase in the methylation level to $83 \%$ in PC3M and to $90 \%$ in PC3 and PC3MLN4 cell lines. The methylation status of the PTGS2 gene increased to 53\% in PC3, to 69\% in PC3MLN4 and to $99 \%$ in PC3M cells. The TIMP2 methylation gradually increased to $73 \%$ in PC3MLN4, to $90 \%$ in PC3M and to $99 \%$ in PC3 cells (Fig. 1). All these genes were hypomethylated in the VH10 cell line (0-3\%).

Moreover, 4 genes: DKK3, MGMT, TNFRSF10D, RARB, were hypermethylated in PC3M and PC3MLN4 cells when compared to the PC3 and VH10 cell lines (Fig. 1). The methylation level of these genes in the VH10 and PC3 cells was in the range $0-3 \%$. The methylation of $D K K 3$ and TNFRSF10D in the PC3M and PC3MLN4 cell lines increased to almost $100 \%$. The MGMT gene showed a methylation level of $58 \%$ in PC3M and $93 \%$ in the PC3MLN4 cells. The RARB methylation level in PC3M and PC3MLN4 cells was 65 and 74\%, respectively. For the GSTP1 gene, a much smaller but statistically significant increase in the methylation level in PC3M and PC3MLN4 compared to the PC3 and VH10 cell lines $(\mathrm{P} \leq 0.01)$ was noted. The GSTP1 methylation level increased from $0 \%$ in PC3 and VH10 to $6 \%$ in PC3M and $15 \%$ in the PC3MLN4 cell line.

No differences were observed in the methylation status of 4 genes: ZNF185, CAVI, MSX1 and DLC1. ZNF185 and MSX1 were hypermethylated, while $C A V 1$ and $D L C 1$ were hypomethylated in all analyzed cell lines. The methylation level of the $C D H 1$ gene exceeded $20 \%$ in all analyzed cell lines: VH10 (21\%), PC3MLN4 (26\%), PC3M (77\%) and PC3 (90\%). Importantly, we found that the PDLIM4 methylation status was higher and achieved statistical significance $(\mathrm{P} \leq 0.01)$ in PC3 (99\%) compared to the VH10 cells, while in other prostate cell lines, the gene was hypomethylated (1\%). 


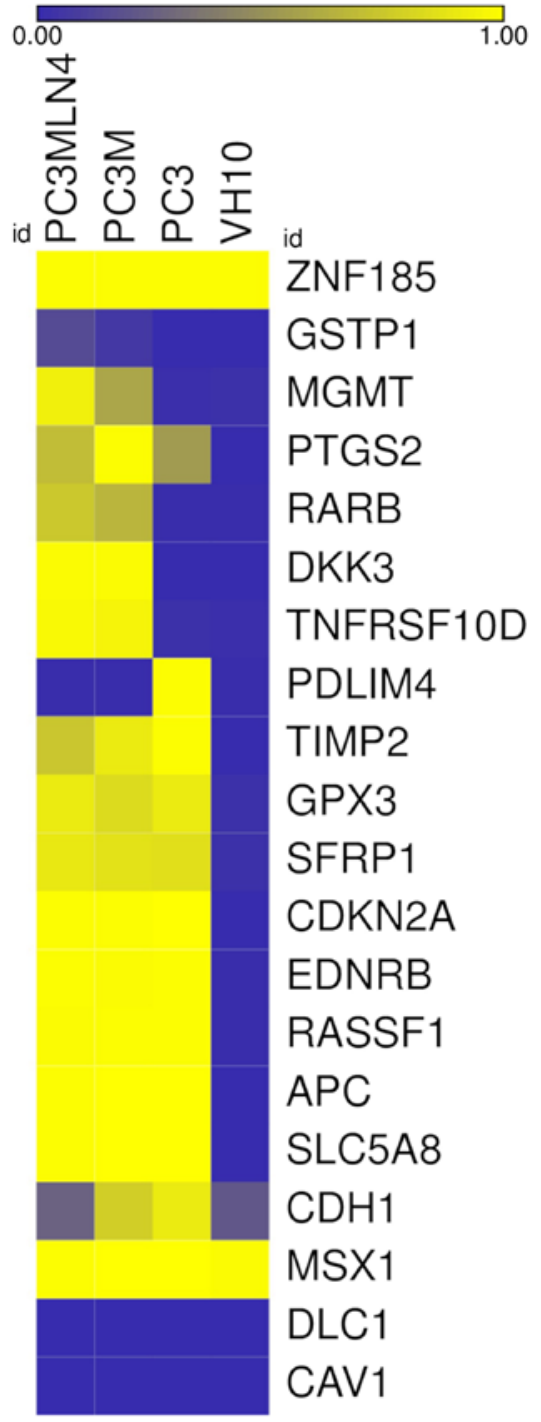

Figure 1. Heatmap of CpG methylation in PC3, PC3M, PC3MLN4 and VH10 cell lines. Each column represents an average of cell line methylation data performed in triplicates; each row represents a described gene. Methylation increases from blue (non-methylated) to yellow (methylated). ZNF185, zinc finger protein 185 with LIM domain; GSTP1, glutathione S-transferase Pi 1; MGMT, O-6-methylguanine-DNA methyltransferase; PTGS2, prostaglandin-endoperoxide synthase 2; $R A R B$, retinoic acid receptor $\beta ; D K K 3$, Dickkopf WNT signaling pathway inhibitor 3; TNFRSF10D, TNF receptor superfamily member 10d; PDLIM4, PDZ and LIM domain 4; TIMP2, TIMP metallopeptidase inhibitor 2; GPX3, glutathione peroxidase 3; SFRP1, secreted frizzled related protein 1; CDKN2A, cyclin dependent kinase inhibitor $2 \mathrm{~A} ; E D N R B$, endothelin receptor type $\mathrm{B} ; R A S S F 1$, Ras association domain family member $1 ; A P C$, APC, WNT signaling pathway regulator; $S L C 5 A 8$, solute carrier family 5 member $8 ; C D H 1$, cadherin $1 ; M S X 1$, Msh homeobox 1; $D L C 1$, DLC1 Rho GTPase activating protein; $C A V 1$, caveolin 1.

Gene expression analysis and its correlation with the methylation pattern. This stage was conducted to ascertain whether methylation of the promoter $\mathrm{CpG}$ island regulates gene expression. For this purpose, gene expression alterations were analyzed using the qPCR method. Gene expression analysis included two further cell lines: One prostate cancer cell line PC3MPro4 (with an increased tumorigenic potential but a low incidence of metastasis) and wild-type fibroblasts, VH25. Gene expression in cell lines with an increasing tumorigenic and metastatic potential was analyzed (PC3MLN4 produced a higher incidence of distant metastases).
APC, DKK3, GPX3, GSTP1, MGMT, PTGS2, RASSF1, TIMP2 and TNFRSF10D gene hypermethylation downregulates gene expression. Genes whose expression was downregulated by hypermethylation were characterized. A high methylation level was associated with a decrease in expression in 9 out of the 20 analyzed genes (APC, DKK3, GPX3, GSTP1, MGMT, PTGS2, RASSF1, TIMP2 and TNFRSF10D). However, hypermethylation caused a different degree of downregulation of these genes. The expression of all genes in prostate cancer cell lines was compared to that in the VH10 cell line.

In the case of 5 of the previously mentioned genes hypermethylated in prostate cancer cell lines versus the fibroblasts, a high methylation level was associated with downregulation of their expression (Fig. 2). The majority of gene expression results were separately normalized in respect to PBGD and $h M R P L 19$. In reactions normalized in respect to $P B G D$, the most significant decrease in expression in prostate cancer cell lines was observed for the PTGS2 gene (10-fold in PC3MLN4 and PC3MPro4, and 6-fold in PC3 and PC3M cells; $\mathrm{P} \leq 0.05)$. TIMP2 expression decreased by gradually increasing factors: 5-fold in PC3MPro4, 8-fold in PC3MLN4, 10-fold in PC3M, and 80-fold in PC3 cells. $A P C$ was downregulated 2 -fold in prostate cancer cell lines. The most significant decrease in RASSF1 expression was noted in PC3M (9-fold), and the lowest in PC3MPro4 ( 3-fold). The GPX3 expression decreased from 12-fold in PC3MLN4 to 100-fold in PC3M when compared to the VH10 cells. However, this observation was based on the GPX3 expression analysis using $h M R P L 19$ as a single reference gene. The level of the GPX3 expression analyzed with $P B G D$ as the reference gene and the TaqMan probe was undetectable (data not shown).

In contrast, DKK3, GSTP1, MGMT and TNFRSF10D were hypermethylated in the PC3M and PC3MLN4 cells, while the methylation level of these genes in the PC3 cell line was similar to that in VH10, close to $0 \%$. A decrease in the expression of these genes was observed corresponding to the hypermethylation of their promoters (Fig. 3.)

The DKK3 gene showed 10-fold lower expression in the PC3 cell line. Other prostate cancer cell lines showed a much greater decrease in the expression of the $D K K 3$ gene (100-fold). The $M G M T$ gene was expressed at the lowest level in PC3MLN4 cells (8-fold lower compared to VH10), while in PC3M and PC3MPro4, the decrease was 2- and 4-fold, respectively. TNFRSF10D was downregulated 2-fold in prostate cancer cell lines. Interestingly, with $h M R P L 19$ as the reference gene, a 3-fold decrease was noted only in PC3, while in other prostate cancer cell lines, TNFRSF10D was expressed at a 4,000-fold lower level compared to VH10. Finally, no statistically significant differences in the expression level of GSTP1 normalized in respect to $P B G D$ were found, thus $G A P D H$ was tested instead. The expression of GSTP1 was downregulated 300-fold in PC3M and PC3MLN4, while in other cell lines it was comparable to the controls. With hMRPL19 as the reference gene, a similar decrease was noted in all analyzed prostate cancer cell lines (3- to 4-fold). The expression of $A P C, D K K 3, P T G S 2, R A S S F 1, T I M P 2$ after normalization in respect to hMRPL19 was also found to be decreased, similarly as when normalized in respect to $P B G D$.

APC, DKK3, GPX3, GSTP1, MGMT, PTGS2, RASSF1, TIMP2, TNFRSF10D methylation pattern in prostate cancer 

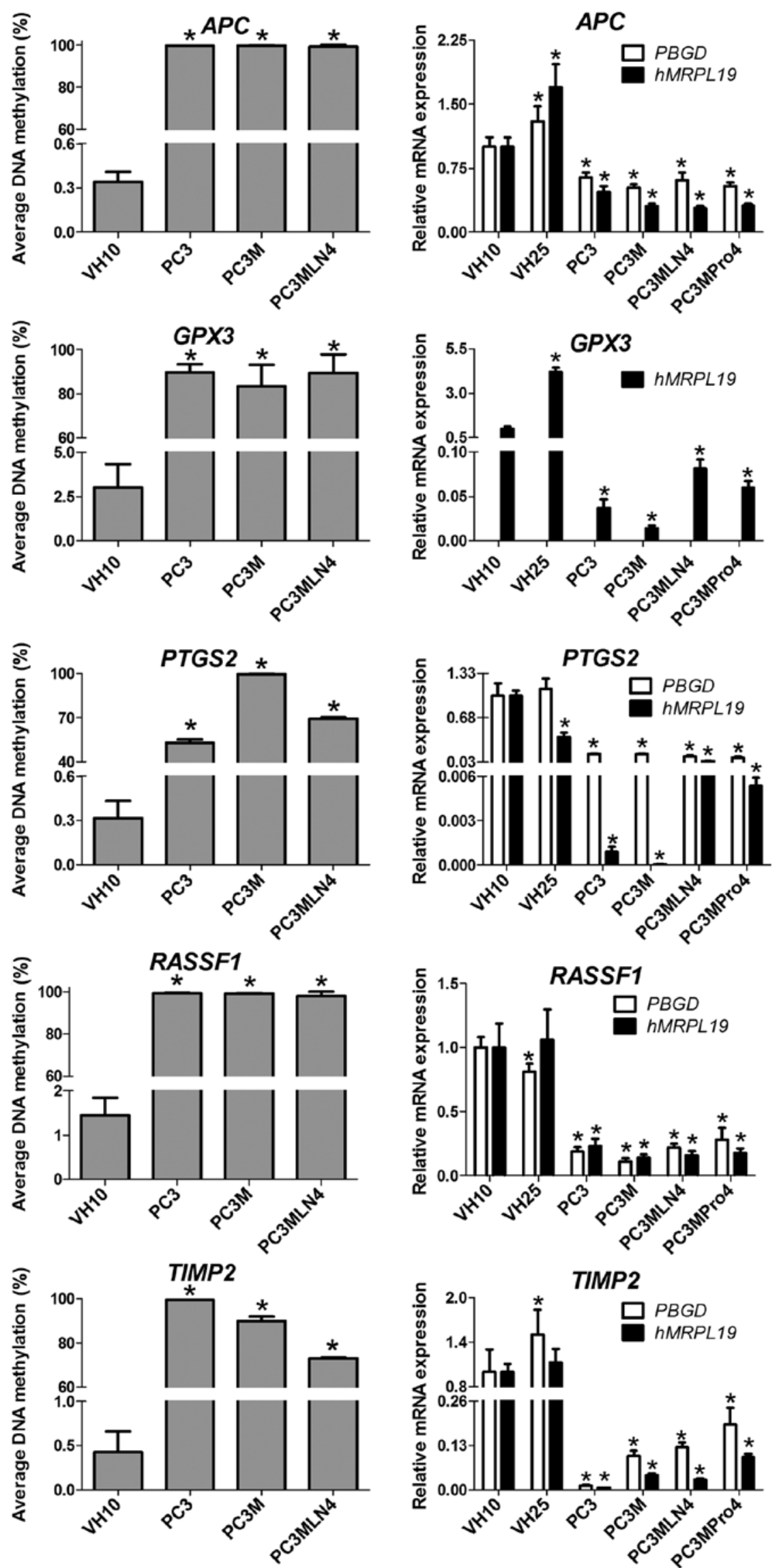

Figure 2. Gene hypermethylation is associated with downregulation of gene expression in prostate cancer cell lines. Left panels show the level of methylation of gene promoters. Gray columns represent an experiment performed in triplicates. Right panels show changes in gene expression. White and black columns represent an experiment performed at least three times in triplicates with PBGD and $h M R P L 19$ used as reference genes, respectively. The GPX3 expression results were obtained using $h M R P L 19$ as a single reference gene. ${ }^{*} \mathrm{P}<0.01$, statistically significant difference in comparison with human VH10 fibroblasts. Error bars, SD. 

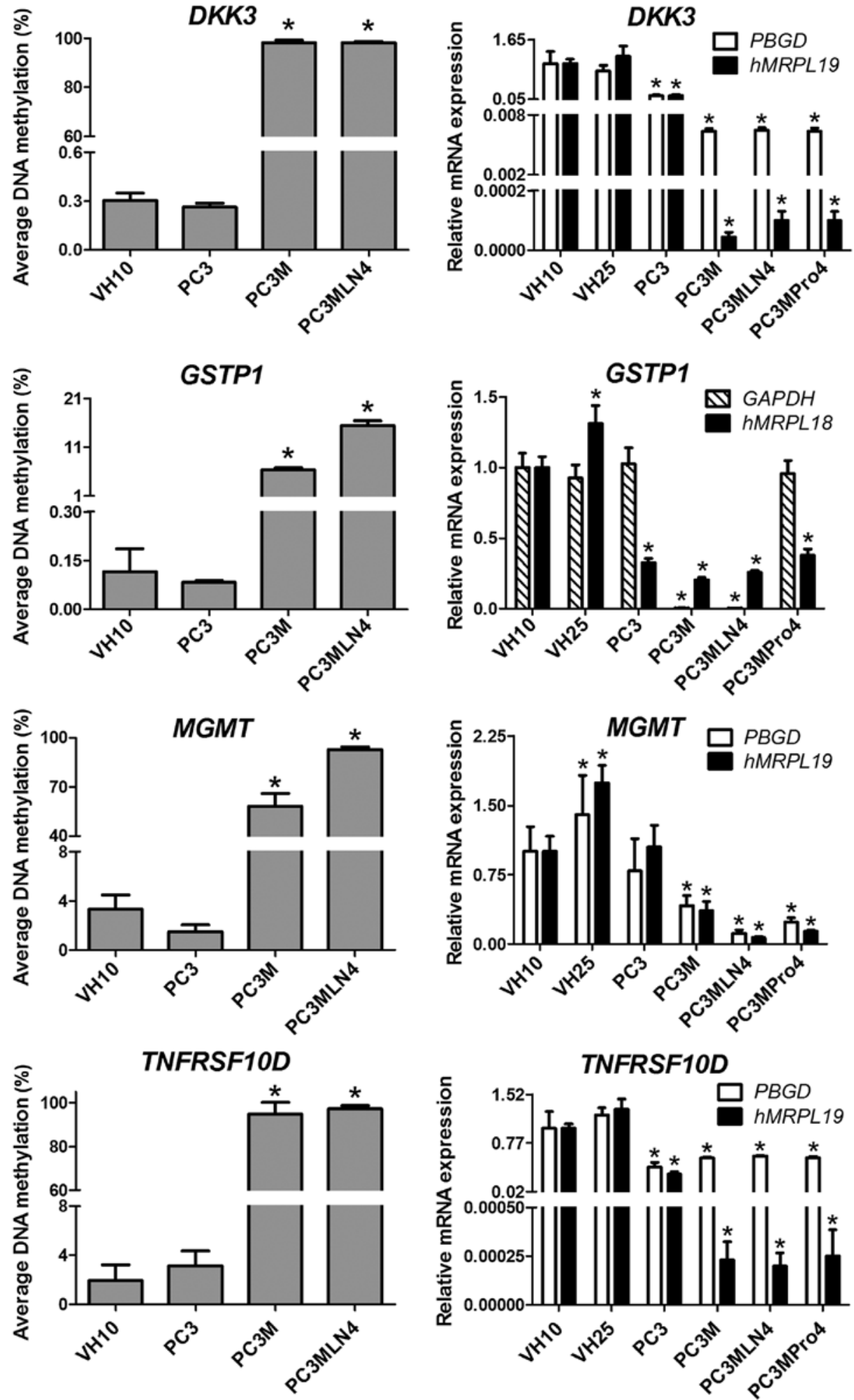

Figure 3. Gene hypermethylation is associated with downregulation of gene expression in PC3M and PC3MLN4 cells compared to PC3 and VH10 cells. Left panels show the level of methylation of gene promoters. Gray columns represent an experiment performed in triplicates. Right panels show changes in gene expression. White, black and striped columns represent an experiment performed at least three times in triplicates with PBGD, hMRPL19 and GAPDH used as reference genes, respectively. ${ }^{*} \mathrm{P}<0.01$, statistically significant difference in comparison with the human VH10 fibroblasts. Error bars, SD.

tissue-in silico analysis. This stage aimed to establish whether the obtained methylation results were consistent with the methylation pattern in prostate cancer tissue. As TCGA is a project which uses high-throughput technologies, it was decided to use integrated human data from TCGA deposited in the
MethHC web base (39,40). The APC, DKK3, GPX3, GSTP1, $M G M T, P T G S 2$, RASSF1, TIMP2 and TNFRSF1OD genes were hypermethylated in prostate adenocarcinoma samples compared to normal samples (which represented a normal tissue from the same group of prostate adenocarcinoma patients) with statistical 


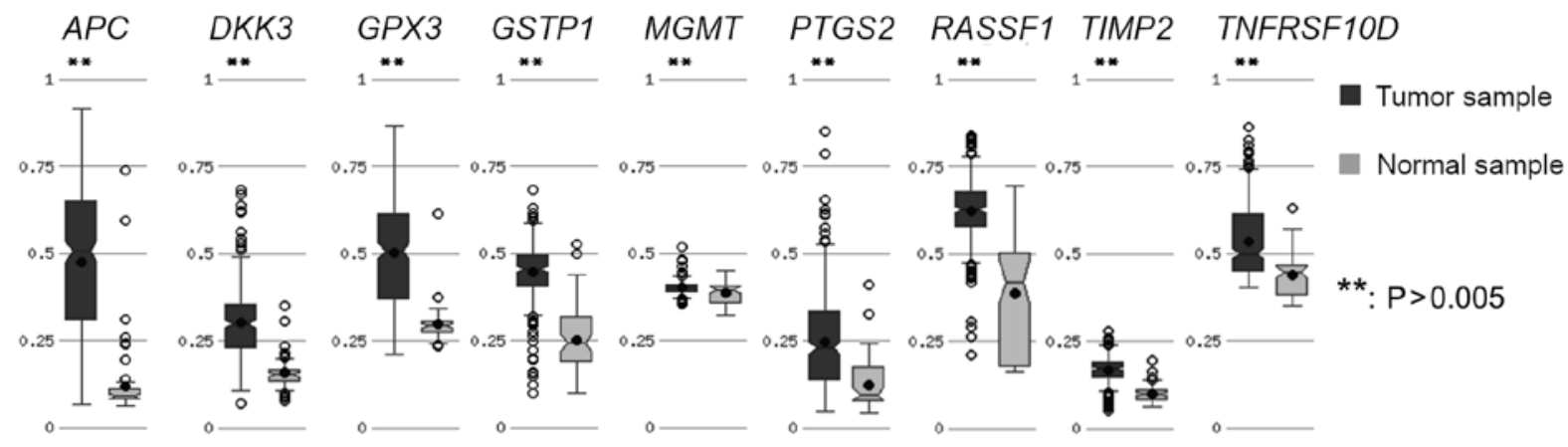

Figure 4. Methylation status of $\mathrm{CpG}$ islands in the promoter regions of human prostate cancer from the MethHC database (39). Analysis showed a significant difference in methylation between all presented genes in normal prostate tissue and prostate adenocarcinoma $\left({ }^{* * *} \mathrm{P} \leq 0.005\right)$. Computational analysis was performed using a dataset (prostate adenocarcinoma TCGA) deposited and tools available under the MethHC open access terms.
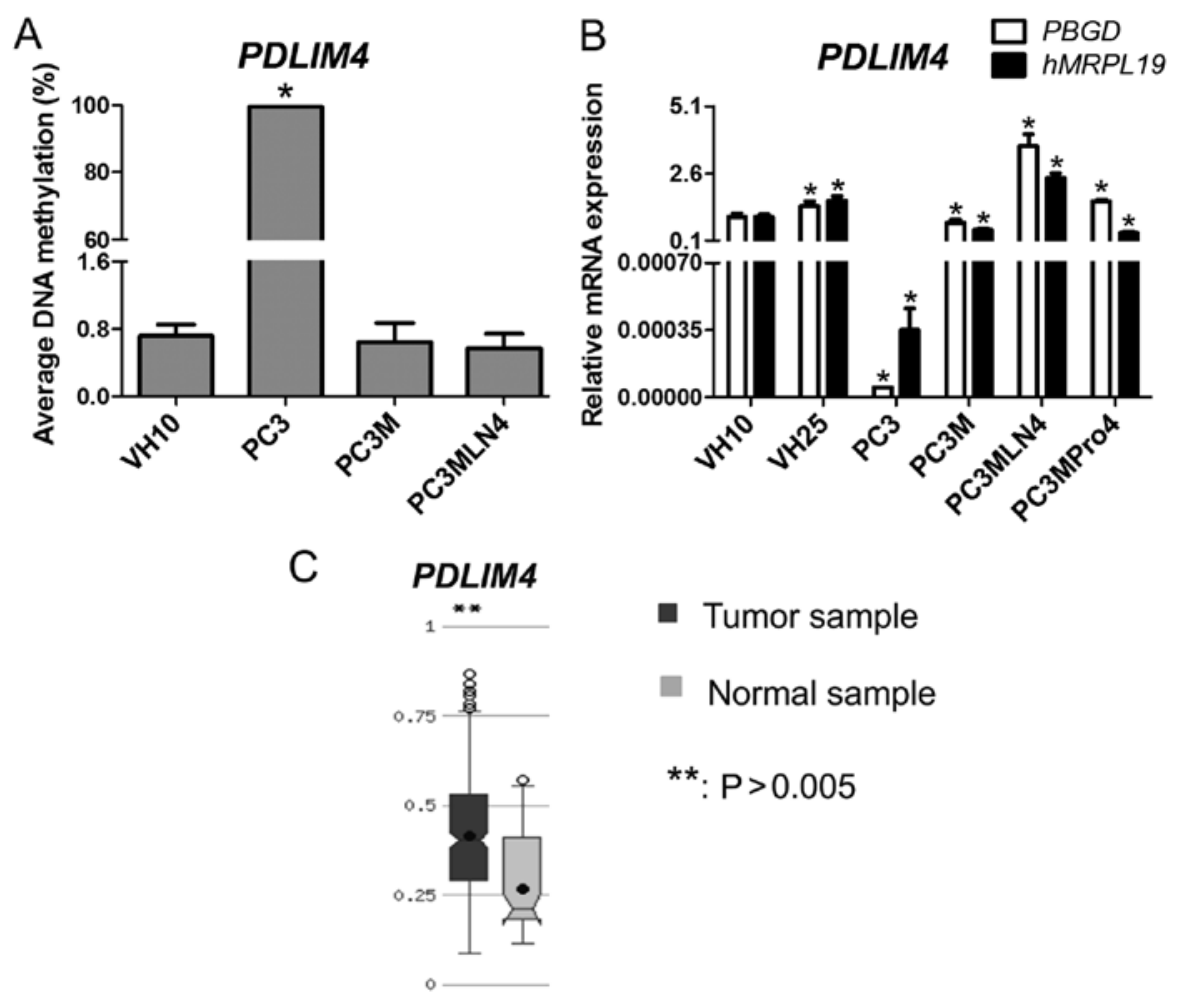

Figure 5. Methylation status of PDLIM4 and its association with expression pattern. (A) PDLIM4 gene hypomethylation is associated with upregulation of gene expression in prostate cancer cell lines and fibroblasts. A shows the level of methylation of gene promoters. Gray columns represent an experiment performed in triplicates. (B) Changes in gene expression are shown. White and black columns represent an experiment performed at least three times in triplicates with $P B G D$ and $h M R P L 19$ used as reference genes, respectively. "P<0.01, statistically significant difference in comparison with the human VH10 fibroblasts. Error bars, SD. (C) Methylation status of PDLIM4 CpG islands in the promoter regions of human prostate cancer tissue from the MethHC database (39). Analysis showed a significant difference between the PDLIM4 methylation in normal prostate tissue and prostate adenocarcinoma $\left({ }^{* * *} \mathrm{P} \leq 0.005\right)$. Computational analysis was performed using a deposited dataset (prostate adenocarcinoma TCGA) and tools available under MethHC open access terms.

significance at $\mathrm{P} \leq 0.005$ (Fig. 4). The greatest difference in the level of methylation between tumor and normal sample was detected in $A P C$, the lowest in MGMT (Fig. 4).

PDLIM4 hypomethylation upregulates gene expression. Genes whose hypomethylation was found to be associated with a significantly higher expression were analyzed. One gene classified to this group, PDLIM4, was hypomethylated in most tested cell lines.

PDLIM4 expression was statistically significantly higher in the PC3M, PC3MLN4 and PC3MPro4 cell lines as well as in fibroblasts compared to that in PC 3 cells. PDLIM4 was hypermethylated in PC3. In other cell lines, PDLIM4 was hypomethylated which was associated with a various degree of gradual increasing expression: PC $3 \mathrm{M}(0.77 \pm 0.13)$, PC3MPro4 (1.56 \pm 0.08$)$ and PC3MLN4 $(3.63 \pm 0.44)$. In the VH10 cell line, PDLIM4 expression was $1.0 \pm 0.14$. According to the TCGA data deposited in MethHC, the PDLIM4 gene was hypermethylated in prostate adenocarcinoma compared to normal samples with statistical significance at $\mathrm{P} \leq 0.005$ (Fig. 5).

Methylation pattern of the DLC1, CAV1, MSX1, ZNF185, $C D K N 2 A, C D H 1, R A R B$ genes is not associated with gene expression. Seven genes (DLC1, CAV1, MSX1, ZNF185, 

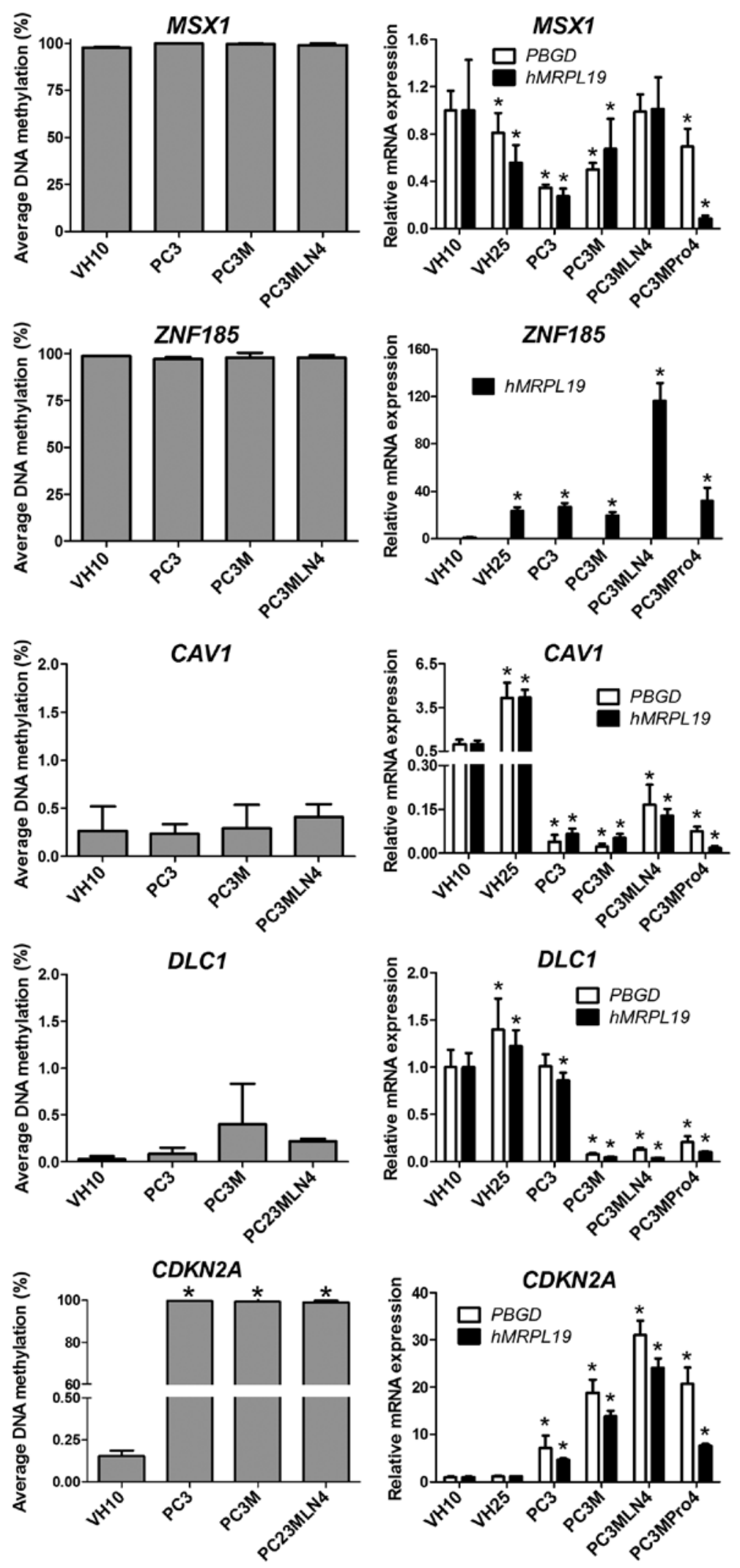

Figure 6. Methylation pattern of $D L C 1, C A V 1, M S X 1, Z N F 185, C D K N 2 A$ genes is not associated with gene expression in prostate cancer cell lines. Left panels show the level of methylation of gene promoters. Gray columns represent an experiment performed in triplicates. Right panels show alterations in gene expression. White and black columns represent an experiment performed at least three times in triplicates with PBGD and $h M R P L 19$ used as reference genes, respectively. ${ }^{\mathrm{P}}<0.01$, statistically significant difference in comparison with the human VH10 fibroblasts. Error bars, SD.

$C D K N 2 A, C D H 1$ and $R A R B)$ whose methylation pattern was not associated with gene expression were distinguished (Fig. 6).
Two genes, DLCI and CAVI, were hypomethylated in fibroblasts as well as in prostate cancer cell lines. Nevertheless, 
differences in the expression levels of these genes were shown. In respect to $P B G D$ as the reference gene, $D L C 1$ expression was at similar level in the PC3 and VH10 cell lines. In the other prostate cancer cell lines, a decrease in expression was found: 5-fold in PC3MPro4, 7.5-fold in PC3MLN4 and 12-fold in

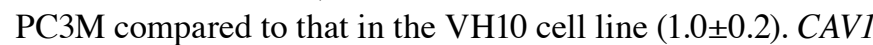
expression was downregulated in all analyzed prostate cancer cell lines: From 40-fold in PC3M to 6-fold in PC3MLN4.

Two other genes, ZNF185 and MSX1, were hypermethylated in all analyzed cell lines. An interesting observation concerned MSX1: When only prostate cancer cell lines were considered, a gradual increase in the relative expression level was observed for PC3 $(0.34 \pm 0.03)$, PC3M $(0.50 \pm 0.05)$, PC3MPro4 (0.69 \pm 0.15$)$, PC3MLN4 $(0.99 \pm 0.15)$. However, $M S X 1$ expression in prostate cancer cell lines was lower than in VH10. The ZNF185 gene was shown to be upregulated in prostate cancer cell lines: 27-fold in PC3, 19-fold in PC3M, 28-fold in PC3MPro4, and 116-fold in PC3MLN4 compared to VH10 cells. Interestingly, the values of relative expression of ZNF185 obtained in PC3, PC3M and PC3MPro4 were comparable with the expression level in the second WT control, VH25. Therefore, they can be considered as falling within the normal range. The ZNF185 expression results were presented with $h M R P L 19$ as the reference gene. In respect to $P B G D$ as the reference, the gene expression pattern was consistent; however, the difference in the expression level between VH10 and PC3MLN4 was much higher (data not shown).

In the case of the $C D K N 2 A$ gene, its methylation pattern as well as expression level differed between prostate cell lines and fibroblasts. Although the $C D K N 2 A$ gene was hypermethylated in prostate cancer cell lines, it was upregulated in these cells compared to VH10 and VH25. The increase in expression was gradual: From 7-fold in PC3, 19-fold in PC3M, 21-fold in PC3MPro4, to 31-fold in the PC3MLN4 cell line.

Expression of DLC1,CAV1, MSX1 and CDKN2A after normalization in respect to $\mathrm{h} M R P L 19$ indicated a pattern similar to that obtained with $P B G D$ as the reference gene. Despite the varied methylation pattern of the $C D H 1$ and $R A R B$ genes in prostate cancer cell lines and fibroblasts, no statistically significant differences in expression level were noted (data not shown).

\section{Discussion}

Abnormal expression of genes in cancer cells can arise from epigenetic changes, but also changes in the number of copies and/or the presence of sequence mutations. Changes in the epigenome are often crucial for the functioning of cells and thus are often associated with carcinogenesis, metastasis and response to chemotherapy. Therefore, unique expression and methylation patterns have been introduced in diagnostics as prognostic and predictive biomarkers. Since the best-known expression profiling performed 15 years ago in breast cancer (41), determination of the unique signature of gene expression $(6,42)$ or promoter methylation is used more frequently, for example $M G M T$ methylation in tumor tissue as a biomarker in glioma (43) or SEPT9 methylation in plasma as a biomarker in colorectal adenocarcinoma (44).

Over the last few years, a broad spectrum of different technologies has been introduced for the quantitative and qualitative measurement of DNA methylation status. The most commonly used method is sodium bisulfite conversion of genomic DNA to differentiate and detect unmethylated and methylated cytosines using methylation-specific PCR, MassARRAY EpiTYPER, hybridization-based promoter and $\mathrm{CpG}$ island microarrays. In this study, a less-known methodology based on input DNA treatment with a methylation-sensitive and methylation-dependent restriction enzyme followed by qPCR was used. Commercial EpiTect Methyl II PCR Array, Signature Panel: EAHS-051Z (Qiagen) kit was selected for methylation analysis in prostate cancer to examine the methylation profile of $\mathrm{CpG}$ islands in 22 cancer-related genes in prostate cancer cell lines with increasing tumorigenic and metastatic potential (30). According to the EpiTect Methyl II PCR Array System manufacturer, every target region is selected within one $\mathrm{CpG}$ island or CpG-dense area predicted from both the UCSC database and published data with functional annotation (45). Further analyses included determination of gene expression and comparison of data from prostate cancer cell lines with the methylation status of $\mathrm{CpG}$ islands in the promoter regions of human prostate cancer from the MethHC database (39).

The expression and methylation status of GSTP1, APC, RASSF1A, MGMT and PTGS2 have previously been well characterized in prostate cancer (46), and gene expression has frequently been evaluated using microarrays. High-throughput methods, such as microarrays, are an excellent screening tool, although the results require validation using quantitative real-time RT-PCR (qPCR) assays. Likewise, the results of methylation profiling have often been obtained using less advanced technologies, such as methylation-specific PCR (MSP) (46). Our study for the first time analyzed these genes in PC3-derived cell lines (PC3M, PC3MLN4 and PC3MPro4) in reference to fibroblasts (VH10 and VH25). qPCR used in this study allowed a precise determination of relative gene expression, normalized in respect to the expression of different reference genes.

According to the results obtained earlier in prostate cancer, it was shown that 12 genes out of 20 analyzed were hypermethylated: 8 genes were hypermethylated in prostate cancer cell lines compared to VH10 (APC, CDKN2A, EDNRB, GPX3, PTGS2, SLC5A8, TIMP2, RASSF1), and 5 genes were hypermethylated in PC3M and PC3MLN4 compared to PC3 and VH10 cell lines (DKK3, MGMT, TNFRSF10D, RARB and GSTP1). Furthermore, 3 genes (CAV1, DLC1, PDLIM4) were found to be hypomethylated in prostate cancer cell lines. Interestingly, methylation was found to regulate the expression of half of the analyzed genes (APC, DKK3, GPX3, GSTP1, MGMT, PDLIM4, PTGS2, RASSF1, TIMP2 and TNFRSF10D) in PC3-derived cell lines and fibroblasts VH10 and VH25.

$A P C$ hypermethylation leads to the stabilization of $\beta$-catenin in the cytoplasm due to deregulation of $\beta$-catenin degradation (10). Previous studies have also demonstrated that $A P C$ hypermethylation is a common occurrence in the PC3 cell line (34), prostate cancer and its progression (47), as well as in other cancers, such as colon and gastric cancer (48).

$D K K 3$ hypermethylation has been observed in pancreatic cancer lines and in breast cancer tissue $(49,50)$. It has been found that this gene is also associated with $\beta$-catenin expression. $D K K 3$ overexpression in transfected cells resulted in a decrease in $\beta$-catenin expression (49). Inactivation of the $D K K 3$ gene is also common in prostate cancer, in which 
the level of the Dkk3 protein is inversely correlated with the Gleason degree, and the lowest level was noted in tumors that are probably metastatic $(51,52)$.

A wide-spectrum analysis of androgen-dependent (LNCaP, and Du145) and androgen-independent (PC3) prostate cancer cell lines allowed characterization of $G P X 3$ as a novel tumor-suppressor gene, as the level of GPX3 expression was associated with prostate tumor stage (35). Our findings in cell lines and the MethHC database are consistent with the widespread hypermethylation of GPX3 in prostate cancer (53-55).

The methylation status of GSTP1, as for $A P C$, is common in prostate cancer $(56,57)$. However, evidence of a relationship between the level of GSTPI methylation and disease progression is contradictory. Some studies have shown that the hypermethylation of this gene is associated with prostate cancer progression (58-60). On the other hand, the prognostic value of GSTP1 methylation has not been demonstrated (47). In our study, methylation as well as the expression level provided prognostic information, but the methylation level increased only to $15 \%$ in PC3MLN4 cells.

$M G M T$ is an important glioblastoma prognostic and predictive biomarker in clinical use (43). Reports regarding prostate cancer are inconclusive $(46,56,61)$. The TCGA results showed that the increase in methylation between tumor and normal tissue was small; however, the difference was statistically significant. On the other hand, MGMT hypermethylation in prostate cancer has been previously reported $(46,61)$. Our results revealed no significant difference in the $M G M T$ methylation level between the PC3 and VH10 cell lines. The MGMT gene was hypermethylated only in the PC3M and PC3MLN4 lines, which was associated with a decrease in expression in these cell lines.

PTGS2 was also hypermethylated in all prostate cancer cell lines compared to fibroblasts. However, the methylation status of PTGS2 varied between the prostate cancer cell lines and it seems that methylation is the main mechanism of PTGS2 regulation in prostate cancer cell lines, as well as in prostate cancer patients-TCGA data (39). Recent studies employing qPCR for methylation analysis have shown that PTGS2 hypermethylation is a potential sensitive and specific prostate cancer biomarker in ctDNA isolated from the blood of PCa patients (62), as well as in prostate cancer tissue (63). Although PTGS2 hypermethylation has been observed in $68 \%$ cases of PCa versus $15 \%$ of $\mathrm{BPH}$ tissues (62), it seems that the methylation status of PTGS2 alone is not sufficient. However, it definitely should be included in molecular profiling to improve efficiency.

A previous study demonstrated that PDLIM4 can function as a tumor suppressor in prostate cancer cells (21). PDLIM4 mRNA expression was found to be reduced in PC3 prostate cancer cells (21), which is consistent with our results, but notably, in other prostate cancer cell lines derived from PC3, PDLIM4 expression increased gradually with the increase in PNC. Our results may suggest a novel oncogenic function of PDLIM4 in prostate cancer cell lines derived from PC3. Putatively, methylation is the main mechanism of PDLIM4 regulation in prostate cancer cell lines, as in renal cancer and acute myelogenous leukemia $(64,65)$.

RASSF 1 hypermethylation, which has been reported in many types of cancers, including prostate cancer, can lead to disorders in the DNA repair pathway and cell cycle control (66). The relationship between the RASSF1 methylation level and prostate cancer aggressiveness has been noted $(66,67)$. Downregulation of TIMP2 has also been correlated with cancer progression and metastasis (68). The results obtained in prostate cancer indicate an antitumor effect of the Timp2 protein (69). However, reports of this phenomenon are contradictory (70). Our results showed hypermethylation of the RASSF1 and TIMP2 genes in prostate cancer cell lines compared to fibroblasts.

Hypermethylation of TNFRSF10D has been noted; for example, in melanoma and prostate cancer $(71,72)$. In prostate cancer cell lines in our study, the TNFRSF10D gene was hypermethylated only in the PC3M and PC3MLN4 cells. Nevertheless, a decrease in expression was observed in all tested prostate cancer cell lines. The TNFRSF10D expression level was similar in all prostate cancer cell lines in respect to PBGD as the reference gene, while with hMRPL19, greater downregulation in PC3M, PC3MLN4 and PC3MPro4 was observed. This observation confirms how important it is to use at least two reference genes for the analysis of relative gene mRNA expression.

It should be noted that the results of $\mathrm{CpG}$ island methylation analysis in the promoter regions obtained in the prostate cancer cell lines for those 10 genes were consistent with clinical data obtained from 336 prostate cancer patients in the TCGA project. Moreover, the methylation signature panel used in this study included genes methylated in prostate cancer cell lines, but no changes in their expression (EDNRB and SLC5A8) were shown. This also included genes with an altered expression level between prostate cancer cell lines and fibroblasts, but was not consistent with the methylation pattern. Those genes are probably regulated by other mechanisms, such as small RNA molecules, e.g., miRNAs (73), changes in chromatin conformation (74) or histone modifications (75).

\section{Acknowledgements}

Not applicable.

\section{Funding}

This research was funded by the Foundation for Polish Science (grant no. HOMING PLUS/2010-2/7) and The Ludwik Rydygier Collegium Medicum, Nicolaus Copernicus University (grant no. MN-SDL-5/WL/2017).

\section{Availability of data and materials}

The datasets used during the present study are available from the corresponding author upon reasonable request.

\section{Authors' contributions}

Conceptualization of the study design was achieved by MAL. The research methodology was conceived by KK, MAL, AB and $\mathrm{SH}$. Software analysis of data was performed by KK and MAL; validation of the data was accomplished by $\mathrm{KK}$; formal analysis was conducted by KK and MAL. Investigation was carried out by KK; resources were the responsibility of JK and MAL. Data curation was performed by MAL. Writing; original draft preparation was carried out by KK and MAL; Writing; review and editing was accomplished by $\mathrm{AB}, \mathrm{JK}$ and $\mathrm{SH}$; visu- 
alization was conducted by KK; supervision was conducted by SH and MAL. Software analysis of data was performed by KK; validation of the data was accomplished by $\mathrm{KK}$; formal analysis was conducted by KK and MAL. Investigation was carried out by $\mathrm{KK}$; resources were the responsibility of JK and MAL; project administration was conducted by JK and MAL; and funding acquisition by MAL. All authors read and approved the manuscript and agree to be accountable for all aspects of the research in ensuring that the accuracy or integrity of any part of the work are appropriately investigated and resolved.

\section{Ethics approval and consent to participate}

Not applicable.

\section{Patient consent for publication}

Not applicable.

\section{Competing interests}

The authors declare no conflict of interest. The funders had no role in the design of the study; in the collection, analyses, or interpretation of data; in the writing of the manuscript, or in the decision to publish the results.

\section{References}

1. The Cancer Genome Atlas-National Cancer Institute. https://cancergenome.nih.gov/ (accessed 2018-10-22), 2011.

2. Baylin SB and Herman JG: DNA hypermethylation in tumorigenesis: Epigenetics joins genetics. Trends Genet 16: 168-174, 2000.

3. Yang M and Park JY: DNA methylation in promoter region as biomarkers in prostate cancer. Methods Mol Biol 863: 67-109, 2012.

4. Golub TR, Slonim DK, Tamayo P, Huard C, Gaasenbeek M, Mesirov JP, Coller H, Loh ML, Downing JR, Caligiuri MA, et al: Molecular classification of cancer: Class discovery and class prediction by gene expression monitoring. Science 286: 531-537, 1999.

5. van't Veer LJ, Dai H, van de Vijver MJ, He YD, Hart AA, Mao M, Peterse HL, van der Kooy K, Marton MJ, Witteveen AT, et al Gene expression profiling predicts clinical outcome of breast cancer. Nature 415: 530-536, 2002.

6. Salazar R, Roepman P, Capella G, Moreno V, Simon I, Dreezen C, Lopez-Doriga A, Santos C, Marijnen C, Westerga J, et al: Gene expression signature to improve prognosis prediction of stage II and III colorectal cancer. J Clin Oncol 29: 17-24, 2011.

7. Guo L, Ma Y, Ward R, Castranova V, Shi X and Qian Y: Constructing molecular classifiers for the accurate prognosis of lung adenocarcinoma. Clin Cancer Res 12: 3344-3354, 2006.

8. Toyota M, Ahuja N, Ohe-Toyota M, Herman JG, Baylin SB and Issa JP: $\mathrm{CpG}$ island methylator phenotype in colorectal cancer. Proc Natl Acad Sci USA 96: 8681-8686, 1999.

9. Shi H, Chen J, Li Y, Li G, Zhong R, Du D, Meng R, Kong W and $\mathrm{Lu} \mathrm{M}$ : Identification of a six microRNA signature as a novel potential prognostic biomarker in patients with head and neck squamous cell carcinoma. Oncotarget 7: 21579-21590, 2016.

10. Voronkov A and Krauss S: Wnt/beta-catenin signaling and small molecule inhibitors. Curr Pharm Des 19: 634-664, 2013.

11. Liu P, Rudick M and Anderson RG: Multiple functions of caveolin-1. J Biol Chem 277: 41295-41298, 2002.

12. Rayess H, Wang MB and Srivatsan ES: Cellular senescence and tumor suppressor gene p16. Int J Cancer 130: 1715-1725, 2012

13. Angst BD, Marcozzi $C$ and Magee AI: The cadherin superfamily: Diversity in form and function. J Cell Sci 114: 629-641, 2001

14. Kim TY, Vigil D, Der CJ and Juliano RL: Role of DLC-1, a tumor suppressor protein with RhoGAP activity, in regulation of the cytoskeleton and cell motility. Cancer Metastasis Rev 28: $77-83,2009$.
15. Niehrs C: Function and biological roles of the Dickkopf family of Wnt modulators. Oncogene 25: 7469-7481, 2006

16. Arai H, Nakao K, Takaya K, Hosoda K, Ogawa Y, Nakanishi S and Imura $\mathrm{H}$ : The human endothelin-B receptor gene. Structural organization and chromosomal assignment. J Biol Chem 268: 3463-3470, 1993.

17. Chen B, Rao X, House MG, Nephew KP, Cullen KJ and Guo Z: GPx3 promoter hypermethylation is a frequent event in human cancer and is associated with tumorigenesis and chemotherapy response. Cancer Lett 309: 37-45, 2011.

18. Hayes JD and Pulford DJ: The glutathione S-transferase supergene family: Regulation of GST and the contribution of the isoenzymes to cancer chemoprotection and drug resistance. Crit Rev Biochem Mol Biol 30: 445-600, 1995.

19. Kaina B, Christmann M, Naumann S and Roos WP: MGMT: Key node in the battle against genotoxicity, carcinogenicity and apoptosis induced by alkylating agents. DNA Repair 6: 1079-1099, 2007.

20. Bonito NA, Borley J, Wilhelm-Benartzi CS, Ghaem-Maghami S and Brown R: Epigenetic regulation of the homeobox gene MSX1 associates with platinum-resistant disease in high-grade serous epithelial ovarian cancer. Clin Cancer Res 22: 3097-3104, 2016.

21. Vanaja DK, Grossmann ME, Cheville JC, Gazi MH, Gong A, Zhang JS, Ajtai K, Burghardt TP and Young CY: PDLIM4, an actin binding protein, suppresses prostate cancer cell growth. Cancer Invest 27: 264-272, 2009.

22. Chandrasekharan NV and Simmons DL: The cyclooxygenases. Genome Biol 5: 241, 2004.

23. Tang D, Kryvenko ON, Mitrache N, Do KC, Jankowski M, Chitale DA, Trudeau S, Rundle A, Belinsky SA and Rybicki BA: Methylation of the RARB gene increases prostate cancer risk in black Americans. J Urol 190: 317-324, 2013.

24. Volodko N, Gordon M, Salla M, Ghazaleh HA and Baksh S: RASSF tumor suppressor gene family: Biological functions and regulation. FEBS Lett 588: 2671-2684, 2014.

25. Mo S, Su Z, Heng B, Chen W, Shi L, Du X and Lai C: SFRP1 promoter methylation and renal carcinoma risk: A systematic review and meta-analysis. J Nippon Med Sch 85: 78-86, 2018

26. Ganapathy V, Thangaraju M, Gopal E, Martin PM, Itagaki S, Miyauchi S and Prasad PD: Sodium-coupled monocarboxylate transporters in normal tissues and in cancer. AAPS J 10: 193-199, 2008.

27. Brew $\mathrm{K}$ and Nagase $\mathrm{H}$ : The tissue inhibitors of metalloproteinases (TIMPs): An ancient family with structural and functional diversity. Biochim Biophys Acta 1803: 55-71, 2010.

28. Pan G, Ni J, Wei YF, Yu G, Gentz R and Dixit VM: An antagonist decoy receptor and a death domain-containing receptor for TRAIL. Science 277: 815-818, 1997.

29. Zhang JS, Gong A and Young CY: ZNF185, an actin-cytoskeleton-associated growth inhibitory LIM protein in prostate cancer. Oncogene 26: 111-122, 2007.

30. Pettaway CA, Pathak S, Greene G, Ramirez E, Wilson MR, Killion JJ and Fidler IJ: Selection of highly metastatic variants of different human prostatic carcinomas using orthotopic implantation in nude mice. Clin Cancer Res 2: 1627-1636, 1996.

31. Wang C, Norton JT, Ghosh S, Kim J, Fushimi K, Wu JY, Stack MS and Huang S: Polypyrimidine tract-binding protein (PTB) differentially affects malignancy in a cell line-dependent manner. J Biol Chem 283: 20277-20287, 2008.

32. Godthelp BC, van BuulPP, Jaspers NG, Elghalbzouri-Maghrani E, van Duijn-Goedhart A, Arwert F, Joenje $\mathrm{H}$ and Zdzienicka MZ: Cellular characterization of cells from the Fanconi anemia complementation group, FA-D1/BRCA2. Mutat Res 601: 191-201, 2006.

33. Wiegant WW, Meyers M, Verkaik NS, van der Burg M, Darroudi F, Romeijn R, Bernatowska E, Wolska-Kusnierz B, Mikoluc B, Jaspers NG, et al: A novel radiosensitive SCID patient with a pronounced $\mathrm{G}_{2} / \mathrm{M}$ sensitivity. DNA Repair 9: 365-373, 2010.

34. Bastian PJ, Ellinger J, Wellmann A, Wernert N, Heukamp LC, Müller SC and von Ruecker A: Diagnostic and prognostic information in prostate cancer with the help of a small set of hypermethylated gene loci. Clin Cancer Res 11: 4097-4106, 2005.

35. Yu YP, Yu G, Tseng G,Cieply K, Nelson J, Defrances M,Zarnegar R, Michalopoulos G and Luo JH: Glutathione peroxidase 3, deleted or methylated in prostate cancer, suppresses prostate cancer growth and metastasis. Cancer Res 67: 8043-8050, 2007.

36. Norton JT, Pollock CB, Wang C, Schink JC, Kim JJ and Huang S: Perinucleolar Compartment prevalence is a phenotypic pancancer marker of malignancy. Cancer 113: 861-869, 2008. 
37. Frycz B, Pinczewska A and Jagodziński PP: Maślan sodu obniża ekspresję dehydrogenazy $17 \beta$-hydroksysteroidowej typu 1-szego W linii komórkowej raka gruczołu krokowego LNCaP. Nowiny Lekarskie 80: 283-287, 2011.

38. Livak KJ and Schmittgen TD: Analysis of relative gene expression data using real-time quantitative PCR and the $2^{-\Delta \Delta C \mathrm{~T}}$ method. Methods 25: 402-408, 2001.

39. Huang WY, Hsu SD, Huang HY, Sun YM, Chou CH, Weng SL and Huang HD: MethHC: A database of DNA methylation and gene expression in human cancer. Nucleic Acids Res 43 D856-D861, 2015.

40. MethHC: A database of DNA methylation and gene expression in human cancers. http://methhc.mbc.nctu.edu.tw/php/index.php. Accessed October 23, 2018

41. van de Vijver MJ, He YD, van't Veer LJ, Dai H, Hart AA, Voskuil DW, Schreiber GJ, Peterse JL, Roberts C, Marton MJ, et al: A gene-expression signature as a predictor of survival in breast cancer. N Engl J Med 347: 1999-2009, 2002.

42. O'Connell MJ, Lavery I, Yothers G, Paik S, Clark-Langone KM Lopatin M, Watson D, Baehner FL, Shak S, Baker J, et al: Relationship between tumor gene expression and recurrence in four independent studies of patients with stage II/III colon cancer treated with surgery alone or surgery plus adjuvant fluorouracil plus leucovorin. J Clin Oncol 28: 3937-3944, 2010.

43. Roszkowski K, Furtak J, Zurawski B, Szylberg $T$ and Lewandowska MA: Potential role of methylation marker in glioma supporting clinical decisions. Int J Mol Sci 17: pii: E1876, 2016.

44. Song L, Peng X, Li Y, Xiao W, Jia J, Dong C, Gong Y, Zhou G and Han X: The SEPT9 gene methylation assay is capable of detecting colorectal adenoma in opportunistic screening. Epigenomics 9: 599-610, 2017.

45. Jiang Q, Liu CX, Gu X, Wilt G, Shaffer J, Zhang Y and Devgan V: EpiTect Methyl II PCR Array System: A simple tool for screening regional DNA methylation of a large number of genes or samples without bisulfite conversion. Qiagen; https://www.qiagen. $\mathrm{com} / \mathrm{ch} /$ resources/resourcedetail?id=39ec06aa-ec53-4acd-aa15-6 7b5882efbb6\&lang=en (cited 2018-11-09).

46. Kang GH, Lee S, Lee HJ and Hwang KS: Aberrant CpG island hypermethylation of multiple genes in prostate cancer and prostatic intraepithelial neoplasia. J Pathol 202: 233-240, 2004

47. Richiardi L, Fiano V, Vizzini L, De Marco L, Delsedime L, Akre O, Tos AG and Merletti F: Promoter methylation in APC, RUNX3, and GSTP1 and mortality in prostate cancer patients. J Clin Oncol 27: 3161-3168, 2009.

48. Llorca-Cardeñosa MJ, Fleitas T, Ibarrola-Villava M, Peña-Chilet M, Mongort C, Martinez-Ciarpaglini C, Navarro L, Gambardella V, Castillo J, Roselló S, et al: Epigenetic changes in localized gastric cancer: The role of RUNX 3 in tumor progression and the immune microenvironment. Oncotarget 7: 63424-63436, 2016.

49. Gu YM, Ma YH, Zhao WG and Chen J: Dickkopf3 overexpression inhibits pancreatic cancer cell growth in vitro. World J Gastroenterol 17: 3810-3817, 2011.

50. Veeck J, Wild PJ, Fuchs T, Schüffler PJ, Hartmann A, Knüchel R and Dahl E: Prognostic relevance of Wnt-inhibitory factor-1 (WIF1) and Dickkopf-3 (DKK3) promoter methylation in human breast cancer. BMC Cancer 9: 217, 2009.

51. Romero D and Kypta R: Dickkopf-3 function in the prostate: Implications for epithelial homeostasis and tumor progression. Bioarchitecture 3: 42-44, 2013.

52. Romero D, Kawano Y, Bengoa N, Walker MM, Maltry N, Niehrs C, Waxman J and Kypta R: Downregulation of Dickkopf-3 disrupts prostate acinar morphogenesis through TGF- $\beta / \mathrm{Smad}$ signalling. J Cell Sci 126: 1858-1867, 2013.

53. Lodygin D, Epanchintsev A, Menssen A, Diebold J and Hermeking $\mathrm{H}$ : Functional epigenomics identifies genes frequently silenced in prostate cancer. Cancer Res 65: 4218-4227, 2005.

54. Yu YP, Paranjpe S, Nelson J, Finkelstein S, Ren B, Kokkinakis D, Michalopoulos G and Luo JH: High throughput screening of methylation status of genes in prostate cancer using an oligonucleotide methylation array. Carcinogenesis 26: 471-479, 2005.

55. Falck E, Karlsson S, Carlsson J, Helenius G, Karlsson M and Klinga-Levan $\mathrm{K}$ : Loss of glutathione peroxidase 3 expression is correlated with epigenetic mechanisms in endometrial adenocarcinoma. Cancer Cell Int 10: 46, 2010.

56. Yegnasubramanian S, Kowalski J, Gonzalgo ML, Zahurak M, Piantadosi S, Walsh PC, Bova GS, De Marzo AM, Isaacs WB and Nelson WG: Hypermethylation of $\mathrm{CpG}$ islands in primary and metastatic human prostate cancer. Cancer Res 64: 1975-1986, 2004.
57. Strand SH, Orntoft TF and Sorensen KD: Prognostic DNA methylation markers for prostate cancer. Int J Mol Sci 15: 16544-16576, 2014.

58. Rosenbaum E, Hoque MO, Cohen Y,Zahurak M,Eisenberger MA, Epstein JI, Partin AW and Sidransky D: Promoter hypermethylation as an independent prognostic factor for relapse in patients with prostate cancer following radical prostatectomy. Clin Cancer Res 11: 8321-8325, 2005.

59. Richiardi L, Fiano V, Grasso C, Zugna D, Delsedime L, Gillio-Tos A and Merletti F: Methylation of APC and GSTP1 in non-neoplastic tissue adjacent to prostate tumour and mortality from prostate cancer. PLoS One 8: e68162, 2013.

60. Bastian PJ, Palapattu GS, Lin X, Yegnasubramanian S Mangold LA, Trock B, Eisenberger MA, Partin AW and Nelson WG: Preoperative serum DNA GSTP1 CpG island hypermethylation and the risk of early prostate-specific antigen recurrence following radical prostatectomy. Clin Cancer Res 11: 4037-4043, 2005.

61. Konishi N, Nakamura M, Kishi M, Nishimine M, Ishida E and Shimada K: DNA hypermethylation status of multiple genes in prostate adenocarcinomas. Jpn J Cancer Res 93: 767-773, 2002.

62. Ellinger J, Bastian PJ, Haan KI, Heukamp LC, Buettner R, Fimmers R, Mueller SC and von Ruecker A: Noncancerous PTGS2 DNA fragments of apoptotic origin in sera of prostate cancer patients qualify as diagnostic and prognostic indicators. Int J Cancer 122: 138-143, 2008.

63. Vasiljević N, Wu K, Brentnall AR, Kim DC, Thorat MA, Kudahetti SC, Mao X, Xue L, Yu Y, Shaw GL, et al: Absolute quantitation of DNA methylation of 28 candidate genes in prostate cancer using pyrosequencing. Dis Markers 30: 151-161, 2011.

64. Morris MR, Ricketts C, Gentle D, Abdulrahman M, Clarke N, Brown M, Kishida T, Yao M, Latif F, Maher ER: Identification of candidate tumour suppressor genes frequently methylated in renal cell carcinoma. Oncogene 29: 2104-2117, 2010.

65. Boumber YA, Kondo Y, Chen X, Shen L, Gharibyan V, Konishi K, Estey E, Kantarjian H, Garcia-Manero G and Issa JP: RIL, a LIM gene on $5 \mathrm{q} 31$, is silenced by methylation in cancer and sensitizes cancer cells to apoptosis. Cancer Res 67: 1997-2005, 2007.

66. Liu L, Yoon JH, Dammann R and Pfeifer GP: Frequent hypermethylation of the RASSF1A gene in prostate cancer. Oncogene 21: 6835-6840, 2002.

67. Maruyama R, Toyooka S, Toyooka KO, Virmani AK, ZöchbauerMüller S, Farinas AJ, Minna JD, McConnell J, Frenkel EP and Gazdar AF: Aberrant promoter methylation profile of prostate cancers and its relationship to clinicopathological features. Clin Cancer Res 8: 514-519, 2002.

68. Imren S, Kohn DB, Shimada H, Blavier L and DeClerck YA: Overexpression of tissue inhibitor of metalloproteinases-2 retroviral-mediated gene transfer in vivo inhibits tumor growth and invasion. Cancer Res 56: 2891-2895, 1996.

69. Pulukuri SM, Patibandla S, Patel J, Estes N and Rao JS: Epigenetic inactivation of the tissue inhibitor of metalloproteinase-2 (TIMP-2) gene in human prostate tumors. Oncogene 26: 5229-5237, 2007

70. Ross JS, Kaur P, Sheehan CE, Fisher HA, Kaufman RA Jr and Kallakury BV: Prognostic significance of matrix metalloproteinase 2 and tissue inhibitor of metalloproteinase 2 expression in prostate cancer. Mod Pathol 16: 198-205, 2003.

71. Ratzinger G, Mitteregger S, Wolf B, Berger R, Zelger B, Weinlich G, Fritsch P, Goebel G and Fiegl H: Association of TNFRSF10D DNA-methylation with the survival of melanoma patients. Int J Mol Sci 15: 11984-11995, 2014.

72. Hornstein M, Hoffmann MJ, Alexa A, Yamanaka M, Müller M, Jung V, Rahnenführer J and Schulz WA: Protein phosphatase and TRAIL receptor genes as new candidate tumor genes on chromosome $8 \mathrm{p}$ in prostate cancer. Cancer Genomics Proteomics 5: 123-136, 2008

73. Catalanotto $\mathrm{C}$, Cogoni $\mathrm{C}$ and Zardo G: MicroRNA in control of gene expression: An overview of nuclear functions. Int J Mol Sci 17: pii: E1712, 2016.

74. Kubiak M and Lewandowska MA: Can chromatin conformation technologies bring light into human molecular pathology? Acta Biochim Pol 62: 483-489, 2015

75. Audia JE and Campbell RM: Histone modifications and cancer. Cold Spring Harb Perspect Biol 8: a019521, 2016.

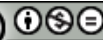

This work is licensed under a Creative Commons Attribution-NonCommercial-NoDerivatives 4.0 International (CC BY-NC-ND 4.0) License. 